\title{
Os museus do vinho em Portugal: COMunicar O PASSADO E COMPREENDER E (RE)CONSTRUIR A HERANÇA CULTURAL VITIVINÍCOLA
}

\author{
Ana Isabel Inácio
}

\begin{abstract}
RESUMO
Os museus do vinho são espaços de visitação, "guardiões" de memória e de discursos sobre o passado e o presente vitivinícola das regiões que representam. Mas são também lugares de integração e de interação entre a história, a identidade, espaços de seleção e exclusão, de memórias subjetivas e seletivas. Estes espaços assumem hoje a dupla função e responsabilidade: por um lado, de preservação, divulgação e (re)produção com rigor científico deste património, mas, por outro lado, comprometem-se em torná-lo lúdico, atrativo e pedagógico, adaptado aos públicos a que se destinam. São por isso agentes fundamentais na construção de uma "cultura do Vinho" nas regiões em que se inserem, que não deixa, porém, de ser seletiva. O número de museus vínicos na região do Douro tem crescido exponencialmente. Para um melhor entendimento da cultura do vinho nesta região e da Identidade que é promovida e valorizada através destes espaços, entendeu-se relevante o estudo dos espólios e respetivo discurso dos museus existentes, através da seleção de uma amostragem significativa destes núcleos. Objetivando-se assim com este estudo o entendimento e o contributo do papel destes museus vitivinícolas para a região do Douro. Da análise realizada pode concluir-se que existe alguma seletividade discursiva que valoriza "os notáveis" históricos da terra, cala muitas vezes clivagens sociais, expressa uma religiosidade vincada, evidencia o árduo trabalho da terra e que não raras vezes se centra nos aspetos técnicos de produção da uva e do vinho e na sua evolução. Muitos destes espaços são recentes e outros foram renovados, percebendo-se que a região reconhece e valoriza a sua existência. Constituem, ainda assim e claramente, uma mais valia para estes territórios do Douro, tanto na sua vertente de animação, como na dinamização e afirmação cultural e identitária que vai muito para além da herança vitivinícola da região. São espaços agregadores de um universo cultural que não se basta no vinho e que permite melhor conhecer a região em que se inserem e que valorizam.
\end{abstract}

\section{The wine museums in Portugal: communicating THE PAST AND UNDERSTANDING AND (RE) BUILDING THE WINE CULTURAL HERITAGE}

\begin{abstract}
The wine museums are spaces of visitation, "guardians" of memory and of discourses about the past and present wine culture of the regions they represent. But they are also places of integration and interaction between history and identity, spaces of selection and exclusion, and also of subjective and selective memories. These spaces today assume two different roles and responsibilities: on one hand, the preservation, dissemination and (re)production with scientific rigor of this heritage, but on the other hand, they commit themselves to make it playful, attractive
\end{abstract}


and pedagogical, adapted to targets and publics. They are therefore vital agents in the construction of a "wine culture", an oenological culture in the regions in which they are integrated, nevertheless remaining selective. The number of wine museums in the Douro region has grown exponentially. For a better understanding of the wine culture in this region and its identity, promoted and valued through these spaces, the present study analyses a significant sample of the existing museums, how they organize and select their discourse. The main goal of this study is to better understand the role of these wine museums in the Douro region, how they help building the local wine culture. From the analysis carried out, it can be concluded that there is some discursive selectivity that values the historical "notables" of the land, the owners, and at the same time it often sheds social cleavages. It can also be noticed a strong religiosity, present in many of the exhibitions and collections. The hard land work is also very visible, centred on the technical aspects of grape and wine production and growth at its evolution for centuries. Many of these spaces are recent and others have been renovated, revealing that the region recognizes and values the existence of wine museums. They are, nevertheless and clearly, an added value for these territories of the Douro, both in their aspect of animation, creating dynamics and building cultural affirmation and identity that goes well beyond the wine heritage of the region. They are spaces that aggregate a cultural universe that represents and values more than the wine itself.

\section{KEYWORDS}

Local identities; wine culture; wine museums; wine tourist

\section{INTRODUÇÃO}

A memória e a sua recuperação tornaram-se numa quase obsessão cultural de grandes dimensões nas sociedades contemporâneas. Vive-se uma espécie de "febre mnemónica" (Nora, 2001, p. 84) em que se reconhece o valor da diversidade cultural, tornando-se relevante a sua reabilitação por forma a entender-se o passado de cada local ou povo. Percebe-se, por um lado, que a História encerra o poder de tornar compreensível o presente e o futuro, porque aquilo que fomos é demasiado importante para se poder compreender aquilo que somos. Por outro lado, existe um crescente interesse turístico na exortação desta diversidade cultural porque se viaja colecionando experiências num contexto em que aquela se tornou relevante e enriquecedora. Num mundo crescentemente globalizado, a diversidade cultural é valorizada e permite alimentar o interesse em experimentar espaços diferentes, em conhecer tempos diferenciados e em tentar compreender as variadas combinações de ambas as dimensões: espaço/tempo.

Os museus nascem enquanto instituições do reconhecimento deste interesse pelo passado, numa primeira fase enquanto coleções particulares, depois disseminando-se e democratizando-se, tornando públicas estas coleções. Posteriormente institucionalizam-se, muitos passam para a propriedade do Estado que os financia e coloca ao serviço das populações, enquanto espaços de memória e de passado.

Numa fase mais contemporânea, vão adquirir novas funções pedagógicas e lúdicas, adaptando-se às sociedades em que se enquadram. Estas instituições não foram também indiferentes à escalada das ferramentas tecnológicas, às adaptações a vários públicos e linguagens, descobrindo novas necessidades de adequação de espólios a 
diferentes acessibilidades, sensibilidades, idiomas e realidades discursivas. Também se disseminam novamente museus privados, museus de diferentes escalas, museus temáticos, museus locais ou com grande especificidade/especialização nas coleções que apresentam. São desafios novos para estas instituições que crescentemente tomam consciência e descobrem novas funções enquanto agentes sociais e reflexivos.

Os museus do vinho e da vinha enquadram-se neste contexto e permitem a vivência e entendimento de uma cultura enológica, mas também o conhecimento das especificidades de cada região em que se enquadram, oferecendo um olhar sobre o seu passado e o seu presente com enorme interesse turístico mas também ao serviço das populações locais, que neles se revêm, permitindo a sua (re)construção identitária.

No presente trabalho questiona-se o papel dos museus vínicos em Portugal enquanto núcleos temáticos da cultura vitivinícola que corporizam. Que papel possuem estes museus no âmbito do fenómeno enoturístico, mas também que tipo de narrativas e relações de seletividade se encontram subjacentes aos seus espólios? Objetiva-se assim melhor compreender este fenómeno cultural, mas também o papel destas instituições neste contexto.

Assim, pretendeu-se, por um lado, conhecer a identidade enológica que os museus vínicos promovem, que identidade e que herança enológica se comunica e de que forma este processo é feito. Por outro lado, visou-se o entendimento dos processos produtivos que se encontram subjacentes a esta identidade. Optou-se por realizar o estudo na mais antiga região vitivinícola demarcada do país, fundada em 1756 e situada na região do Douro, por ser também aquela que apresenta aproveitamento turístico há mais tempo em termos nacionais e aquela que possui uma maior variedade de modalidades de enoturismo e práticas turísticas associadas na atualidade. Este património e esta identidade são explorados e foram organizados há mais tempo do que em outras regiões, sendo que as visitas às caves e adegas situadas em Gaia remontam aos anos quarenta do século XX (Inácio, 2008). Em consequência, é a que possui um maior número de unidades de análise: museus do vinho e da vinha ou museus locais onde a temática do vinho também se encontra presente (Museus do Douro, 2011).

Pretende-se que este estudo possa ser transposto para outras regiões e núcleos museológicos um pouco por todo o país, algo que se pensa fazer a longo prazo, sendo o presente estudo exploratório, por forma a obter por comparação, não apenas o mapeamento da diversidade identitária existente, mas também das semelhanças e diferenças destes espólios e identidades, ricos por natureza. Este exercício de reflexão é não só importante cientificamente para a comunidade académica que estuda o turismo ou a museologia, mas também constitui um contributo reflexivo acerca das identidades locais, da cultura enológica e da sua diversidade regional em Portugal. Pretendendo-se um melhor entendimento das opções de narrativa cultural que em cada uma das unidades e regiões se fizeram. 


\section{CONTRIBUTOS PARA O ESTUdo DOS MUSEUS DO VINHO: METOdOLOGIA, OBJETIVOS E HIPÓTESES DE TRABALHO}

Assumindo como premissa que os museus do vinho e da vinha em Portugal contribuem para o conhecimento e a afirmação da herança e da identidade enológica da região que representam, as hipóteses de estudo equacionadas foram: (H1.) As narrativas históricas dos processos produtivos fazem-se a par do entendimento dos processos sociais que lhe estão subjacentes. ( $\mathrm{H}_{2}$.) As especificidades locais encontram-se destacadas nestas narrativas. ( $\mathrm{H}_{3}$.) Estas identidades e espaços têm relevância tanto para a atividade turística como para as comunidades locais em que se integram, legitimando esta herança cultural.

Porque esta realidade é complexa, optou-se pelo recurso a fontes primárias e secundárias para a abordagem ao locus de observação, existindo intervenção direta e visitação das unidades identificadas.

A abordagem metodológica centrou-se fundamentalmente numa análise qualitativa de conteúdo, interessando aferir discursos, narrativas e dinâmicas através da observação dos espólios existentes. Optou-se por realizar uma análise de conteúdo das exposições existentes nestes vários espaços, utilizando-se grelhas de observação e uma análise qualitativa dos dados recolhidos. Partiu-se do universo de unidades museológicas existentes na região (Museu do Douro, 2011) e tentou integrar-se o maior número de casos possível, tendo por opção analisar apenas as unidades sob a designação de Museus (e não de Espaços Museológicos), pelo menos numa primeira fase do trabalho, sendo que se atentou à diversidade da sua distribuição na própria região: Baixo Corgo, Cima Corgo e Douro Superior, região que perfaz cerca de 250 mil hectares (IVDP, 2015) por forma a obter significância e representatividade amostral.

Por último, recorreu-se a fontes secundárias, optando-se pela análise dos dados que foram facultados por algumas destas instituições, e também aqueles que se encontram disponíveis na internet e que dão conta das atividades desenvolvidas por estas instituições. Teve-se ainda em consideração, e por suporte, estudos realizados há perto de uma década sobre os mesmos espaços (Inácio, 2008) e que nos permitiram uma análise comparativa dos espólios existentes e da forma como estes evoluíram e foram adaptados à realidade e objetivos que estes núcleos hoje apresentam, proporcionando uma dupla perspetiva analítica: uma de evolução temporal e outra de análise atual das exposições permanentes existentes e dos espaços em que se encontram, que em alguns casos foram alterados.

\section{OS MUSEUS: ESPAÇOS DE REPRESENTAÇÃo DE PODER E DE (RE)CONSTRUÇÃo SIMBÓLICA DA REALIDADE}

A valorização da "memória e do passado" remonta ao período do Renascimento italiano, período em que as elites sociais valorizavam objetos da Antiguidade e também alguns mais singulares, meras curiosidades, que recolhiam nas suas viagens, e aos quais conferiam valor artístico e histórico (Anico, 2000) mas também um certo status 
social. Era uma forma de valorização dos seus detentores e das suas experiências de viagem. Surgiam assim, nas Cortes Europeias renascentistas coleções de raridades e preciosidades trazidas de geografias outras, contribuindo para a criação de uma grande diversidade de espólios privados de famílias abastadas que, cultivando o gosto pelo colecionismo, constituiriam aquilo que seria a "semente" da organização dos primeiros museus (Faria, 1995).

Este interesse foi continuado e alimentado pelo Historicismo do século XIX, que apesar de ter sido amplamente criticado por Nietzsche por ser aniquilador das forças criativas e por se exceder e centrar no culto do passado, não permitindo espaço para a inovação (Ribeiro, 2014), foi porém muito relevante na medida em que possibilitou que o passado e a sua compreensão, a história das civilizações e das culturas, fossem ganhando relevância e interesse, materializando-se em espólios e peças que foram sendo "colecionados" e que permitiram organizar e "construir" um discurso acerca desse passado.

As coleções que se apresentam nos museus são, por isso, e desde a sua origem seletivas e representam as escolhas de quem as organizou, lhes pretendeu dar um "alinhamento" e significado e não raras vezes têm subjacente uma construção de discurso espartilhada por circunstâncias culturais, políticas, ideológicas e até por interesses pessoais, tendo em conta muitas vezes aquilo que os seus mecenas permitem ou objetivam.

Os museus revelam-se assim sistemas de significação caraterísticos de um tempo histórico específico, sendo socialmente contingentes e envolvendo, em simultâneo, formas de interação social e modos de perceção (Faria, 1995). Mas frequentemente é esquecido o facto de a História estar repleta de narrativas e parcialidades que permitem muitas vezes a (re)construção do passado (Foucault, 1992; Hobsbawm \& Ranger, 1985). A esta parcialidade acresce ainda a parcialidade dos sujeitos envolvidos: daquele que narra, que observa e interpreta e a do recetor que escuta e também interpreta com a sua perceção, sendo também ele seletivo nas mensagens que se disponibiliza a receber (Berger \& Luckman, 1972). Igualmente, no universo das crónicas e testemunhos escritos registados para os anais, os interesses e visões particulares de mecenas são recorrentes.

No caso dos museus acresce o facto de serem instituições cujo papel social se discute. Apesar de se reconhecer o caráter de rigor científico na organização do espólio, os museus acumulam hoje a obrigação simultânea de se adaptarem a vários públicos e linguagens, um discurso que se quer simultaneamente pedagógico e lúdico, obrigando a opções de forma e conteúdo e a uma seleção consciente e criteriosa de factos e destaques, também eles (re)construções simbólicas do real.

De acordo com o ICOM (2001), o museu define-se como uma instituição permanente sem finalidades lucrativas, que serve a sociedade e o seu desenvolvimento, encontrando-se aberto ao público e que adquire, preserva, investiga, comunica e exibe material que se consubstancia como testemunho dos seres humanos e do seu ambiente, tendo por finalidade proporcionar o seu estudo, educação ou fruição. Por isso se percebe que, os museus objetivam hoje, de forma clara, o propósito de fornecer símbolos culturais agregadores, cujo propósito concorre para o sentimento de pertença, permanência e continuidade em relação ao passado, contribuindo para a consolidação de identidades 
coletivas, independentemente da escala ou dimensão destas identidades. Este fenómeno revela-se de particular valor e interesse no quadro da globalização e do turismo, promovendo particularidades de forma instrumental, permitindo colocar a tónica na diversidade cultural e na sua valorização, formatando-a para consumo, direcionada para vários públicos, linguagens e sensibilidades.

\section{MuSEUS, DO NACIONAL AO LOCAL: ESPAÇOS DE PODER, DE SABER OU DE ENTRETENIMENTO?}

Os museus consubstanciam-se como espaços "guardiões" de memória e de discurso sobre o passado, constituindo-se como lugares de integração, interpretação e dialética entre a história e as identidades, memórias subjetivas e seletivas (Kavanagh, 1996, 2000). Organizam discursos e espólios sobre a realidade, legitimando identidades e sociabilidades, refletindo lógicas de poder que consciente ou inconscientemente ajudam a decidir o futuro e a entender o que somos, o que fomos e o que seremos. Seguindo esta mesma lógica, os museus locais assumem funções idênticas, mas de microescala e de menor projeção, favorecendo a afirmação de localismos, regionalismos, e pluralismos, valorizando-os (Desvallés, 1993) ou, como afirma Faria (1995, p. 173), "os museus locais refletem a história das comunidades locais". Mas nem sempre foi assim, o espaço museológico foi temporalmente sujeito a alterações, tanto dos seus objetivos e funcionalidades como na natureza da sua propriedade.

Os trabalhos das autoras portuguesas Faria (1995) e Anico (2000) assumem-se de referência no entendimento destas instituições e na sua evolução. Segundo Faria, é possível distinguir claramente fases na evolução dos espaços museológicos desde a sua génese, de coleções privadas que a classe burguesa foi adquirindo, aos espaços museológicos do século XIX que tinham como missão educar as populações, passando para espaços espetacularizados e lúdicos de fruição cultural. Anico (2000), com uma década de distância, advoga a relevância dos museus regionais e municipais para a construção de identidades, e a sua significação e valorização cultural, estudando em profundidade os Museus Municipais de Loures e desenvolvendo aquilo que atualmente é pensado, pretendido e atribuído a estes núcleos museológicos como objetivos e funções.

Os museus hoje constituem-se como espaços de "representação de poder" e de (re)construção de um passado em que se apresentam perspetivas e narrativas diversas sobre a realidade. São espaços de negociação e diálogo, de produção de significados partilhados com diversos públicos (Desvallés, 1993) e desejavelmente adaptados no discurso a estes vários públicos. Este último aspeto, porém, não é consensual. Para alguns autores estamos na era da sociedade espetáculo (Debord, 1967) ou na era do vazio (Lipovetsky, 1989) ou na sociedade do hiperconsumo (Lipovetsky, 2006), em que se assiste à personalização e customização de experiências, e à "espetacularização" da vida real dos cidadãos e da sociedade mas em certa medida também, e segundo as correntes mais críticas, a algum esvaziamento e pauperização de conteúdos. Segundo esta lógica os museus devem permanecer espaços "guardiões" de cultura e de qualidade dos conteúdos representados, resistindo a estas formatações de "época". São vários os autores e 
estudos de referência nesta área que lançam o debate sobre o papel dos museus nas sociedades contemporâneas. Na perspetiva aqui apresentada, os museus adaptaram-se a estes tempos constituindo-se como espaços de lazer e educação (Faria, 2001; Maccannell, 1976; Urry, 1999), onde o edutainement tem lugar. Autores como Pearce (1992) e Urry (1999) falam até de pós-museus conferindo um novo significado e funcionalidade aos núcleos museológicos que assumem assim um papel educativo, lúdico e funcional nas sociedades que representam e também para as populações que os visitam.

\section{OS MUSEUS DA VINHA E DO VINHO: ESPECIFICIDADES}

Os museus vínicos são núcleos museológicos temáticos que se constituem como lugares que preservam uma memória seletiva onde a cultura e o património que legitimam e representam se relacionam com uma "identidade enológica" da região. A cultura ligada ao vinho e ao cultivo da vinha apresenta em algumas partes do globo, como no caso português, uma história longa, que remonta ao período paleolítico. Nestes espaços de múltiplas funcionalidades celebra-se o vinho como produto, invenção civilizacional e preconiza-se o seu entendimento enquanto parte de uma cultura associada a determinada região. As questões espácio-temporais são relevantes nesta cultura, mas as questões de contexto e de entendimento das sociedades também.

Nas funções dos museus do vinho e da vinha encontramos duas fundamentais: são espaços que promovem a cultural local com relevância para as comunidades e populações de proximidade, ou seja, integrando produtos culturais, mas desempenham também funções e apresentam potencialidades turísticas, revelando-se componentes fundamentais de produtos turísticos, nomeadamente enoturísticos e gastronómicos, ou até de turismo cultural, entre outros. Possuem um claro papel de valorização, explicação, interpretação, criação, exposição de identidades e diversidades locais e regionais para quem visita estas regiões, proporcionado o seu entendimento.

Constituem-se assim como lugares de representação de memórias e conhecimento da "cultura enológica" numa dupla perspetiva: a) por um lado, estes núcleos visam oferecer aos seus públicos a compreensão dos processos produtivos, pois também estes evoluíram no tempo e no espaço, em função das especificidades locais, características do território e das culturas a estes associadas; b) por outro lado, estes espaços permitem a compreensão da realidade enológica do ponto de vista da cultura local, daqueles que são os intervenientes históricos, notáveis mas também anónimos que se incluem e encontram representados em cada uma das regiões e que se situam, no espetro das suas identidades regionais. $A$ (re)construção de identidades culturais revela-se assim central como objeto e funcionalidade destes espaços, funcionalidade estudada de forma aprofundada por Handler e Gable (1997) que estimulam e contribuem para a criação de uma dupla visão acerca desta realidade; a do visitante e a do visitado; a da comunidade local e a dos turistas e visitantes, consolidando assim o processo de referentes e identidades locais.

Conclui-se, assim, que a valorização das identidades locais é uma realidade que produz autoconhecimento mas também se reflete na autoestima, na capacidade de reter 
capital humano e massa crítica nestes locais, contribuindo para o desenvolvimento local (Inácio, 2008). A sua relevância enquanto espaços de cultura, pedagógicos, de entretenimento, de relacionamento e de comunicação de identidades é indiscutível no quadro de realidades regionais onde a presença da cultura e do cultivo do vinho faz parte do ADN das populações, permitindo chegar à perceção das suas lógicas evolutivas e ao entendimento das questões fundamentais e estruturantes das culturas locais aqui representadas.

\section{CASO DE ESTUdo: os MUSEUS Do Vinho E DA VINHA DA REgIÃo DEMARCADA Do Douro}

No Douro os vestígios de produção vitivinícola remontam à pré-história (Barreto, 1993). A região demarcada existe desde 1756, sendo das mais antigas do mundo. A história deste povo e deste território foi, por isso, e desde sempre marcada pela presença da produção de vinho e pelo cultivo da vinha, assim tornado traço distintivo de cultura local. Existem grupos, classes, imigração, migração, habitares, lógicas de sociedade que na região se fundamentam nestas caraterísticas de herança patrimonial que gira em torno do património enológico. Ainda hoje permanecem no território descendentes de famílias nacionais e também estrangeiras que secularmente trabalham a terra e produzem vinho de reputação mundial, sendo dominante a presença de pequenos e médios produtores.

Existem grandes casas de tradição ancestral onde se incluem famílias inglesas há várias gerações, mas também grandes grupos económicos, que manifestam interesse pela oportunidade que o território proporciona na produção de vinhos únicos.

No Douro tem-se assistido nas últimas décadas a uma melhoria significativa da qualidade das produções do território, existindo vinhos medalhados, de mérito e prestígio internacional. Na região acontecem feiras do vinho que conseguem alcançar projeção e dimensão idênticas, plasmando a dinâmica pujante da indústria vitivinícola existente na região, que produz uma grande variedade de vinhos, entre os quais o Vinho do Porto.

O turismo que se desenvolve na região é substancialmente marcado por esta especificidade vitivinícola. O "Vale do Douro" foi o primeiro destino que recebeu um SMED (System for Measuring Excellence in Destinations) do CED (Centro de Excelência de Destinos, ONG reconhecida pela OMT) em 2008. Os turistas procuram então o seu conhecimento e não são exclusivamente enoturistas. Os turistas culturais, de turismo urbano ou de muitas outras formas de turismo, reconhecem esta caraterística da região e manifestam interesse em conhecer o terroir, um território que possui características geomorfológicas muito diferenciadas e/ou experimentar os vinhos da região.

A paisagem vinhateira das encostas do Rio Douro foi uma "invenção humana", "arrancada" a pulso à natureza, que domesticada, aplanada em "mortórios", profundamente transformada, foi-se moldando e tornando favorável a esta produção. São, porém, terrenos muito difíceis de trabalhar, a história assim nos ensina. A paisagem vinhateira foi premiada pela Unesco em 2001, potenciando ainda mais e dando maior visibilidade a este património cultural enquanto recurso turístico para a região e para o país. E tanto a 
Estratégia Nacional de Turismo 2027 como o anterior PENT (2006) consideram a região e esta forma de turismo estratégicas para o desenvolvimento turístico do país.

“O Douro é Vinho" (Barreto, 1993, p. 9) e a sociedade na região é marcada por esta omnipresença. Mas na região existem três grandes unidades territoriais com caraterísticas distintas: Baixo Corgo, Cima Corgo e Douro Superior. Na produção de vinhos cada uma das regiões possui histórias e funcionalidades relativamente distintas, sobretudo na produção de Vinho do Porto. Tradicionalmente, é na zona mais interior e agrícola que acontece o processo produtivo. Já mais litorais são as zonas de envelhecimento, armazenamento, transporte e comercialização, onde se incluem as Caves e Adegas na Foz, beneficiando da centralidade do Porto, segunda maior cidade do país. Mas não se produzem apenas vinhos do Porto na região, muitos outros de grande prestígio e renome são aqui produzidos e geram interesse cultural e turístico, com diferentes proveniências.

As modalidades de enoturismo presentes na região são diversas e contemplam vários itinerários integrados que sugerem visitas a Quintas, Caves ou Adegas; é possível o alojamento em várias destas Quintas ou em Unidades de Turismo no Espaço Rural ou de Turismo de Habitação, mas também em várias unidades hoteleiras de luxo, projetos de grande prestígio alicerçados na região. Também existem Cruzeiros no Douro em vários troços do rio, destinados a distintos públicos, alguns de curta duração, outros mais onerosos que permitem pernoitar a bordo e ir conhecendo e parando ao longo do rio. São também possíveis passeios de comboio ao longo do Douro, na linha que acompanha o rio ou ainda passeios de helicóptero, a partir do Porto. Acontecem, ao longo de todo o ano, feiras e festas do vinho e mostras gastronómicas, de escala local, nacional e internacional, em que se prova e promovem estes produtos. Mencione-se ainda o projeto das "Aldeias Vinhateiras", que consistiu na recuperação e dinamização do património de aldeias em 2001 que foram consideradas elegíveis sob esta designação e que hoje são espaços de visitação disponíveis. Finalmente, os museus do vinho e da vinha, perto de 13 unidades, e outras unidades museológicas onde, para além do vinho, outras manifestações culturais estão presentes.

Quanto aos museus do vinho e da vinha na região, desde logo destaca-se o facto de terem mais do que duplicado as estruturas existentes na última década. Assim, existem atualmente treze estruturas que incluem museus do vinho, núcleos ou espaços museológicos dedicados ao vinho (Museus do Douro, 2011). A presente análise incidiu sobre sete das treze estruturas existentes (50\% do total). A região possui das mais antigas, mas também das mais modernas e recentes, infraestruturas do país, tanto públicas como privadas. Na seleção amostral atendeu-se à sua dimensão e distribuição geográfica: duas unidades em Vila Nova de Gaia, uma no Porto, uma no Peso da Régua, uma no Pinhão, uma em São João da Pesqueira e a última em Foz Côa.

Existe no território a Rede de Museus do Douro, cujo principal dinamizador é o Museu do Douro no Peso da Régua (Mud). Este museu tem vindo a auxiliar outras instituições privadas com a mesma natureza e objetivo a organizar as suas coleções e a desenvolver os seus núcleos, garantindo assim alguma harmonia nos objetivos destes espaços em termos de representação e espólio disponíveis. 
Do trabalho realizado podem destacar-se algumas especificidades que se consideram relevantes, e que decorreram de uma análise sistematizada dos espaços e dos seus espólios, e que em nosso entender contribuíram para a prossecução dos objetivos do presente trabalho.

Verifica-se globalmente que os processos produtivos e as técnicas agrícolas utilizadas na região para a produção do vinho constituem uma constante destes espólios, destacando-se sobretudo as dinâmicas económicas geradas no ciclo produtivo, mais do que as questões humanas e relacionais entre aqueles que trabalham o vinho.

A grande maioria das coleções, pelo espólio que possui, destaca o caráter secular de produção de vinho na região. Em Foz Côa ele é associado a peças do século I, mas a maioria das peças de muitos destes espaços datam dos séculos XVIII, XIX e XX. É claro o destaque que se dá à experiência secular de produção tanto de produtores individuais: casas de produção em particular, como de produtores que em associação anónima contribuíram para esta produção e cultura.

O discurso é maioritariamente organizado de forma diacrónica, enfatizando-se as relações e as dificuldades que decorreram do domínio do terroir na região, da relação com o rio Douro para o transporte destes vinhos, da dureza dos solos, do mau tempo e intempéries, as doenças e moléstias da vinha, o clima, o pó e o difícil trabalho dos socalcos, a constituição dos mortórios e as várias técnicas de transporte, engarrafamento, amadurecimento e armazenamento que foram responsáveis pelo engrandecimento progressivo dos vinhos produzidos na região.

Quanto à "identidade enológica”, percebe-se que o discurso encontra-se mais centrado nas especificidades das técnicas de trabalho produtivo do que nas relações sociais que este produz. Sabe-se muito mais sobre o trabalho agrícola do que sobre as pessoas que o protagonizam. As relações sociais de hierarquia, as questões de propriedade, de classes e hierarquias humanas não são claras no discurso organizado. Encontram-se esbatidas e discretas. Sendo o trabalho produtivo altamente especializado e fruto de hierarquias sociais e até de questões de género muito bem vincadas, estes traços não se encontram evidenciados no discurso organizado. Destacam-se, muitas vezes figuras em particular, personagens que se notabilizaram por serem grandes proprietários e protagonistas na região: a Ferreirinha, George Sandman, o Conde de Oeiras Sebastião José de Carvalho e Mello (Marquês do Pombal), Adriano e António Ramos Pinto, entre outros. Mas o povo e a relação com os trabalhadores aparecem "limpos" de conflitos e "neutros" na sua representação. Isso acontece mesmo quando a presença dos ingleses é forte e as diferenças de género muito marcadas nos papéis instrumentais existentes em todo o processo de produção, engarrafamento, rotulagem, transporte e comercialização, ou até as questões de classe vincadas pelas diferentes funções associadas a todo este processo. Ou seja, as questões relacionais não são claramente uma prioridade no entendimento destas representações. Os espaços privados muitas vezes aproveitam para colocar em destaque a história das famílias que estão na origem da casa que representam.

Existe, porém, um denominador comum que em muitos dos espólios se encontra representado. Em muitos dos quadros expostos, em filmes, em pinturas e em vários 
locais analisados está presente a figura do "divino". Por isso, é possível perceber que a identidade local é marcada por uma religiosidade vincada, de grande devoção católica cristã, transversal aos agentes representados: a bênção das vindimas, da produção e do plantio; a Virgem que acompanha os barcos rabelos e os protege de intempéries e percalços que espreitam os marinheiros no difícil transporte das pipas até à Foz.

Os rótulos de cada marca e a sua evolução, numa lógica de comunicação e representação gráfica são também uma constante em muitos destes núcleos. Constituem-se assim manifestamente como espaços de análise fértil de comunicação do valor destas marcas e da importância dos referentes associados ao vinho. Percebe-se facilmente a evolução e sofisticação gráfica que estas imagens de produto foram tendo ao longo dos tempos e que acompanham a qualidade e a crescente projeção internacional dos vinhos e marcas que representam. As garrafas utilizadas e a sua evolução são também uma das presenças quase sempre contempladas nestas coleções.

Nos espólios existentes é fácil a leitura da dinâmica económica proporcionada por esta atividade na região, embora nem sempre exista referencia direta a este facto. Nos registos sobre a produção e exportação de vinho, nos inventários existentes, nos valores comerciais que os registos expostos apresentam, é fácil ler e perceber esta dinâmica.

Vários dos núcleos existentes, tanto públicos como privados, utilizam recursos eletrónicos e os novos media como suportes na organização do seu discurso, dando em alguns casos uma vertente lúdica e interativa aos espaços, mais próxima e apelativa dos públicos mais jovens. Destacam-se a este respeito os Museus de São João da Pesqueira, a nova estrutura do Museu do Douro no Peso da Régua.

Vários são os núcleos que apresentam um espaço para passar breves filmes sobre esta realidade possuindo, alguns, coincidências em termos de conteúdos. É o caso dos Museus do Vinho do Porto e do Museu do Douro no Peso da Régua. Excertos do filme de um núcleo podem ser visionados no outro.

Alguns destes espaços são recentes ou foram recentemente remodelados e muitos dos projetos arquitetónicos que albergam estes espólios são eles mesmos de grande interesse e relevância cultural. Alguns apresentam interesse histórico: a reconversão de antigos armazéns ou lagares.

Em todos estes espaços são possíveis a aquisição de vinho e a sua degustação, publicações ou merchandizing relacionado com esta cultura em loja ou em espaço contíguo à exposição permanente. Ou seja, a experiência turística e/ou cultural passa por degustar o vinho da região, tendo a possibilidade de aquisição do mesmo em todos os locais estudados. Do que se pode concluir que esta será uma questão relevante para todos os agentes envolvidos na análise, não apenas porque proporciona mais valias económicas para o núcleo em causa, mas porque a experiência da cultura do vinho passa pela "apresentação" in loco dos vinhos e produtos que neste território se concebem.

Muitos destes espaços, nomeadamente os museus públicos, possuem a particularidade de acolher eventos culturais e sociais das comunidades locais: exposições, congressos, encenações, exposições temporárias, ateliês, entre outros, proporcionando alguma criação de eventos e dinamização cultural na região em que se inserem. 
Funcionam assim como núcleos de valorização cultural, para além de espaços de significação e representação cultural, potenciando a cultura enquanto elemento vivo e indo ao encontro dos interesses e necessidades das comunidades locais.

\section{Conclusões}

Na região do Douro, os núcleos museológicos existentes são recentes ou foram recentemente remodelados. Constituem um capital cultural importante para a região em que se inserem, possuindo uma dupla função de espaços de afirmação de identidades locais: aqueles que se encontram mais junto ao Porto (em Vila Nova de Gaia, Foz) recebem maioritariamente públicos estrangeiros, turistas, e os que se encontram no interior do território (no Peso da Régua ou em São João da Pesqueira) possuem uma presença considerável de públicos de proximidade, nomeadamente os escolares, para além dos turistas. Desempenham assim um papel importante, porque ajudam os jovens e crianças locais a perceber melhor a história e as caraterísticas da região em que vivem e as atividades que a dinamizam. Para além do papel que desempenham na construção de uma imagem junto dos turistas. Considera-se que esta é uma função importante destes espaços e um enorme contributo par a afirmação das identidades locais.

Também, por isso, se entendeu pertinente avaliar as narrativas existentes. A este respeito, considera-se que em muitos dos casos existe pouca dinâmica ou adaptação de informação e conteúdos a diferentes públicos ou linguagens. Ainda assim, e comparando com o ano de 2008 em que se fez uma primeira análise dos espaços, existe uma melhoria considerável em vários deles, nomeadamente nas adaptações em termos de acessibilidades de públicos com necessidades especiais ou nos idiomas em que a informação veiculada se encontra. Algumas instalações foram mesmo substituídas por novas, como é o caso do Museu do Douro, no Peso da Régua e está também prevista a relocalização do Museu do Vinho do Porto, para um novo espaço.

Existe em todos os espaços visitados uma clara orientação para o turista e para a experiência turística, apelando a mais do que um sentido, já que para além do espaço expositivo existe sempre a possibilidade de degustação do vinho da região.

O discurso é centrado no entendimento do vinho através do seu processo produtivo e das dinâmicas económicas criadas, relevando para segundo plano as questões sociais presentes nesta atividade, nomeadamente as de género ou hierarquia social. $A$ identidade que se "celebra" é em certa medida "pacífica". Por vezes destacam-se protagonistas individuais, frequentemente proprietários ou personagens históricos que deixaram a sua marca na região, mas numa lógica de enobrecimento das suas ações e contributos para a dinamização desta produção.

Muitos destes museus, nomeadamente os privados, não cobram entradas ou praticam tarifas em que existe a possibilidade de aplicação de diversos descontos, tornando muito acessível a experiência. Ainda assim, pode considerar-se que estes espaços, para além de gerarem dinâmica social e cultural, geram também alguma dinâmica económica, lucros que advêm de entradas e de vendas em loja, ainda que os níveis de 
empregabilidade qualificada e o número de postos de trabalho implicados nestas unidades não sejam elevados.

Quanto às hipóteses formuladas neste trabalho considera-se que a hipótese $1\left(\mathrm{H}_{1}\right.$.) refuta-se, já que "as narrativas históricas dos processos produtivos" refletem pouco daquilo que são "os processos sociais que lhe estão subjacentes". Já no que se refere à (H2.) "As especificidades locais encontram-se destacadas nestas narrativas", a hipótese confirma-se. As narrativas demonstram que o trabalho no Douro é único, os mortórios, os Rabelos, todo o processo produtivo, o terroir e as suas caraterísticas, a convivência com o rio e as condições geomorfológicas são condições singulares de paisagem e território bem destacadas nas exposições existentes. Já no que respeita à ( $\mathrm{H}_{3}$.) "estas identidades e espaços têm relevância tanto para a atividade turística como para as comunidades locais em que se integram legitimando esta herança cultural", a hipótese confirma-se. São importantes na dinamização da cultura do passado e do presente tanto para os públicos internos como externos, recebendo turistas e públicos de proximidade. Constituem assim uma mais valia para os territórios em que se inserem, na sua vertente de animação, dinamização e afirmação cultural que vai muito para além da herança vitivinícola da região.

\section{REFERÊNCIAS}

Anico, M. (2000). Museus e pós-modernidade. Lisboa: ISCSP.

Barreto, A. (1993). Douro. S.I.: Edições Inapa.

Berger, P. \& Luckman, T. (1972). The social construction of reality. Londres: Penguin Books.

Debord, G. (1967). A sociedade do espetáculo [ebook]. Retirado de https://www.marxists.org/portugues/ debord/1967/11/sociedade.pdf

Desvallés, A. (1993). La museographie des musées dits de 'societé': raccorci historique. In E. Barroso \& E. Vailant (Eds.), Musées et Sociétés, Actes du Colloque Mulhouse Ungersheim (pp. 130-136). Paris.

Faria, M.L. (1995). Museus: educação ou divertimento. Revista Crítica de Sociais Sociais, 43, $171-195$.

Foucault, M. (1992). O que é um autor? Lisboa: Vega.

Handler, R. \& Gable, E. (1997). The new history is an old museum. Creating the past at Colonial Williamsburg. Durham: USA: Duke University Press.

Hobsbawm, E. \& Ranger, T. (1985). The invention of tradition. Cambridge: Cambridge University Press.

ICOM (2001). Definição de museu. Retirado de http://icom-portugal.org/recursos/definicoes/

Inácio, A. I. (2008). Da cultura do vinho ao vinho como cultura. Tese de Doutoramento em Geografia, Planeamento Regional e Urbano, Faculdade de Letras, Universidade de Lisboa, Lisboa, Portugal. Retirado de http://repositorio.ul.pt/handle/10451/550

Inácio, C. (2002). Os museus de cidade em Portugal. Os museus da cidade de Lisboa. Um estudo de caso. Tese de Mestrado em Museologia, Universidade de Évora, Évora, Portuga. 
IVDP (2015). A Região Demarcada do Douro. Retirado de https://www.bportugal.pt/sites/default/files/O2._ contributo_manuel_de_novaes_cabral_-_ivdpip.pdf

Savannah, G. (Ed.) (1996). Making histories in museums. Londres e Nova lorque: Leicester University Press.

Kavanagh, G. (2000). Dream spaces. Memory and the museum. Londres e Nova lorque: Leicester University Press.

Lipovesky, G. (1983) A era do vazio - ensaio sobre o individualismo contemporâneo. Lisboa: Relógio d’Água.

Lipovesky, G. (2006). A felicidade paradoxal - a sociedade do hiper-consumo. Lisboa: Edições 70.

Maccannell, D. (1976). The tourist: a new theory of the leisure class. Califórnia: University of Califórnia Press.

Museu do Douro (2011). A vinha e o vinho em Portugal, museus e espaços museológicos. Peso da Régua, Portugal: Museus do Douro.

Nora, P. (2001) (1984). Rethinking France. Les lieux de mémoire, Vol. I. Chicago: The State, Chicago \& University of Chicago Press.

Nora, P. (2002). The reasons for the current upsurge in memory. Tr@nsit-Virtuelles Forum, 22. Retirado de https://www.eurozine.com/reasons-for-the-current-upsurge-in-memory/

Pearce, S. (1992). Museums, objects and collections. A cultural study. Leicester: Leicester University Press.

Ribeiro, V. S. (2014). Nietzsche e a crítica à ideia de progresso e ao historicismo do século XIX: para um novo ideal de cultura (Buldung). Cadernos de Educação Tecnologia e Sociedade, 6, 273-280. Retirado de http:// cadernosets.inhumas.ifg.edu.br/index.php/cadernosets/article/view/200/103

Urry, J. (1999). The tourist gaze. Leisure and travel in contemporary societies. Londres: Sage.

\section{NOTA BIOGRÁFICA}

Professora Auxiliar Convidada no Instituto Superior de Turismo e Hotelaria do Estoril (ESHTE) em Portugal, desde 2009 e Investigador Sénior do Terriur, Centro de Investigação do Centro de Estudos Geográficos do Instituto de Geografia e Ordenamento do Território da Universidade de Lisboa (CEG/IGOT).

Doutora em Geografia, Planeamento Regional e Urbano pela Faculdade de Letras da Universidade de Lisboa (2009) e mestre em Sociologia, Comunicação, Cultura e Tecnologias da Informação pelo ISCTE, Lisboa (1999). Licenciada em Comunicação Social e Cultural pela Universidade Católica Portuguesa de Lisboa (1997) e Bacharel em Gestão de Turismo pela ESHTE (1995).

Email: ana.inacio@eshte.pt

Morada: Escola Superior de Hotelaria e Turismo do Estoril, Av. Condes de Barcelona, n 808, Estoril, 2769-510 Cascais Portugal

* Submetido: $28-02-2018$

* Aceite: 15-07-2018 